\title{
Risk of hypertension in school-aged children with different parental risk: a longitudinal study from childhood to young adulthood
}

Parisa Amiri ${ }^{1}$, Marjan Rezaei ${ }^{1}$, Sara Jalali-Farahani ${ }^{1}$, Mehrdad Karimi ${ }^{1}$, Leila Cheraghi ${ }^{1}{ }^{12}$, Romina Esbati ${ }^{1}$ and Fereidoun Azizi ${ }^{3 *}$

\begin{abstract}
Background: Although previous studies have shown the relationship between different parental factors and children's blood pressure status, there is limited data on the cumulative effect of these factors. Considering parental socio-demographic, behavioral and cardio-metabolic characteristics, the current study aimed to distinguish parental risk clusters and their impact on the incidence of hypertension in school-age children over 13 years.

Methods: Parental characteristics of 1669 children, including age, education, employment, smoking, physical activity, metabolic syndrome (MetS), hypertension (HTN), weight status, and diabetes were considered to categorize parents into low and high-risk clusters. Crude incidence rates (per 10,000 person-years) of HTN in children were assessed in each maternal and paternal cluster. Using Cox proportional hazard model, results on the association between parental risk clusters and HTN incidence in children were reported in five different models.

Results: Mean age of children was $13.96 \pm 2.89$ years, and $51.2 \%(n=854)$ were girls. MetS, HTN, and weight status were the most important factors distinguishing low and high-risk parental clusters, respectively. Crude incidence rates (per 10,000 person-years) of HTN were 86 (95\% Cl: 71-106) and $38(95 \% \mathrm{Cl}, 29-52)$ in boys and girls, respectively. Moreover, incidence rates (per 10,000 person-years) of HTN were 50 (95\% Cl, 40-63) and $80(95 \% \mathrm{Cl}$, 64-102) in maternal low and high-risk clusters, respectively. The incidence rates (per 10,000 person-years) of HTN in paternal low and high-risk clusters were 53 (95\% Cl, 41-70) and 68 (95\% Cl, 56-84), respectively.

Conclusion: Our findings underscore the prognostic value of maternal characteristics in predicting the incidence of HTN in their offspring. The current results could be valuable in planning related programs to prevent hypertension in similar communities.
\end{abstract}

Keywords: Hypertension, Childhood, Parental risk

\footnotetext{
* Correspondence: azizi@endocrine.ac.ir

${ }^{3}$ Endocrine Research Center, Research Institute for Endocrine Sciences,

Shahid Beheshti University of Medical Sciences, P.O.Box: 19395-4763, Tehran,

Islamic Republic of Iran

Full list of author information is available at the end of the article
}

C C The Author(s). 2021 Open Access This article is licensed under a Creative Commons Attribution 4.0 International License, which permits use, sharing, adaptation, distribution and reproduction in any medium or format, as long as you give appropriate credit to the original author(s) and the source, provide a link to the Creative Commons licence, and indicate if changes were made. The images or other third party material in this article are included in the article's Creative Commons licence, unless indicated otherwise in a credit line to the material. If material is not included in the article's Creative Commons licence and your intended use is not permitted by statutory regulation or exceeds the permitted use, you will need to obtain permission directly from the copyright holder. To view a copy of this licence, visit http://creativecommons.org/licenses/by/4.0/ The Creative Commons Public Domain Dedication waiver (http://creativecommons.org/publicdomain/zero/1.0/) applies to the data made available in this article, unless otherwise stated in a credit line to the data. 


\section{Introduction}

Hypertension (HTN) plays a pivotal role in increasing the risk of cardiovascular diseases (CVD) [1]. The World health organization (WHO) has recently reported that 1.13 billion people suffer from HTN worldwide [2]. Prehypertension (pre-HTN) and HTN are relatively common in Iran, with approximately one-quarter of Iranian adult populations being hypertensive, the prevalence being higher among elderly populations [3]. In addition, findings of a national survey indicates an alarming rate of high blood pressure in Iranian adolescents, with a high constant trend in both rural and urban areas [4]. Although childhood HTN may not result in HTNrelated complications, as usually happens in adults, early stages of complications such as left ventricular hypertrophy (LVH), early or structured atherosclerosis and microalbuminuria do occur in hypertensive children [5]. In addition, data available shows that hypertensive children and adolescents are more likely to suffer from high blood pressure in adulthood, indicating the importance of identifying its related risk factors to prevent this public health crisis in the early years of life [6].

Several hereditary, behavioral, anthropometric, and socio-environmental risk factors underlying HTN in children and adolescents $[7,8]$. In this regard, the attributive role of children's BMI, physical activity, dietary habits, gender and ethnicity in the development of HTN have been investigated previously. Of all these factors, obesity plays a significant role in the incidence of HTN in this age group [5]. In addition, existing data on adolescents shows that blood pressure (BP) is higher in boys, African-Americans, individuals who are less physically active, and those with higher salt consumption [9, 10]. Beyond personal factors, more studies emphasize the importance of the family history of HTN in the elevation of their offspring's BP $[9,11]$. It has been documented that having a history of HTN in both parents, vs one parent magnifies the risk of children's HTN [12]. Moreover, regarding other parental characteristics, relatively few studies have investigated the association between offspring's HTN and parental education, smoking and socio-economic status (SES) independently and their findings showed higher rates of adolescents' HTN and pre-HTN among smoker parents and those with lower education and SES [13-15].

In the Middle-East region, the limited data available regarding parental risk factors of childhood HTN is controversial. While some studies indicate the role of family history of HTN and obesity [16-19], others found no significant contribution of these factors in the development of high BP in children [20, 21]. In Iran, the family history of HTN and obesity has been suggested to be an independent risk factor for children's HTN [17]. Despite the synergic effects of the aforementioned parental factors on childhood HTN, most previous studies have investigated the association between these factors and childhood HTN separately, resulting in inconsistent findings. Hence, the current research, for the first time, aimed to investigate the association between parental risk clusters and incidence of HTN in offspring in an Eastern-Mediterranean population over a 13-year follow-up.

\section{Methods}

Data for this study was extracted from Tehran Lipid and Glucose Study (TLGS), an ongoing community-based study, initiated in 1999-2001aimed at determining noncommunicable diseases (NCD) and their related risk factors in an urban population. The TLGS was designed with two main junctures: Phase I, a cross-sectional study of the prevalence of NCDs and their risk factors, implemented from 1999 to 2001; and Phase II, a prospective follow-up study along with lifestyle interventions and triennial data recollection. Five follow-up re-exams have been carried out from 2002 until 2017 every 3 years. Details on protocol, design, and data collection of the TLGS have been discussed elsewhere [22, 23]. In brief, TLGS participants were selected using a multistage cluster random sampling from three random medical health centers in district 13, located in the eastern part of Tehran. From a total of 15,005 (age, $\geq 3$ years) individuals, who had agreed to participate and signed the consent forms, all school-aged children without HTN at baseline $(n=2848)$ and their parents were recruited for the current study, of which 572 children lacked complete parental data, and 607 individuals were lost to follow-up. The remaining 1669 children and their parents were included in the cluster analysis (Fig. 1).

\section{Study variables}

In the current study children's HTN was considered as the outcome variable. Paternal and maternal risk clusters have been considered as the main predictors of the incidence of HTN in offspring. Parental risk clusters have been defined using socio-demographic (age, education, and employment status), behavioral factors (physical activity and smoking), and cardio-metabolic factors (metabolic syndrome, diabetes, HTN, and weight status). Children's age, sex, and BMI have been considered as potential confounders.

\section{Measurements}

Measurements were obtained by trained research staff according to the standard protocols [22-24]. Weight was measured with minimum clothing and no shoes using a digital scale. Height was measured while participants were standing with shoulders in normal alignment and without shoes. BMI $\left(\mathrm{kg} / \mathrm{m}^{2}\right)$ was calculated to 


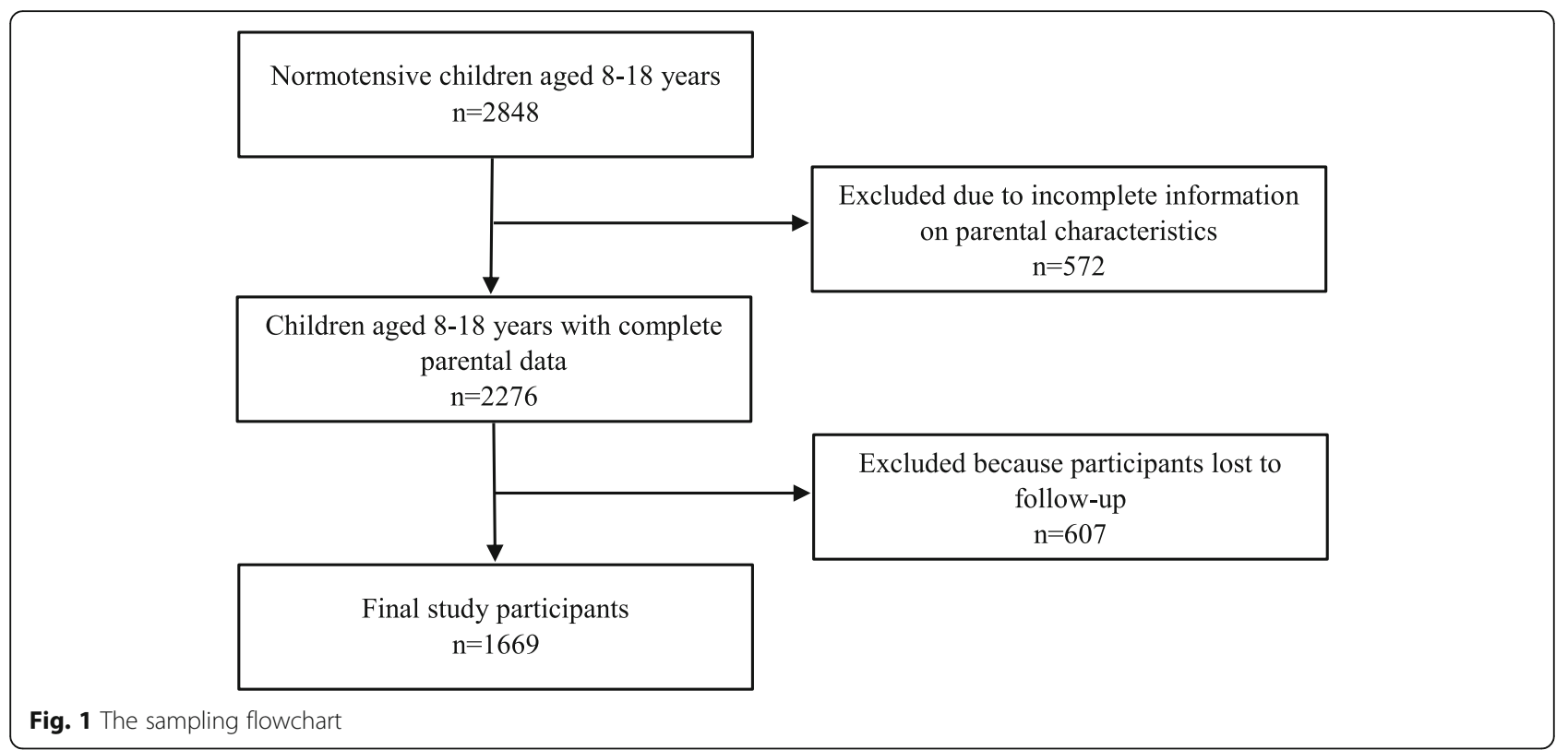

determine weight status in parents and participants aged $\geq 19$ years. Blood pressure was measured twice at 30-s intervals on the right arm at the heart level, while participants were in a relaxed sitting position using a standard mercury sphygmomanometer calibrated by the Iranian Institute of Standards and Industrials Researches. Three different cuffs (pediatrics, regular adult, and large cuff) were available suited for different arm circumferences. Blood pressure was recorded in millimeters of mercury. HTN in adults was defined as systolic blood pressure $(\mathrm{SBP}) \geq 140 \mathrm{mmHg}$, diastolic blood pressure (DBP) $\geq 90$ $\mathrm{mmHg}$, or taking antihypertensive medications. For adolescents, HTN was defined as blood pressure equal or greater than the 95th percentile, specific for age, gender and height $[25,26]$. Diabetes in parents was defined as fasting blood glucose (FBG) $\geq 126 \mathrm{mg} / \mathrm{dl}$ or 2 -h postglucose challenge $\geq 200 \mathrm{mg} / \mathrm{dl}$ or receiving medications for a definite diagnosis of diabetes. For determining MetS in parents, it was defined according to the joint interim statement, as the presence of any three of the following five risk factors: (1) abdominal obesity with a waist circumference $\geq 95 \mathrm{~cm}$ for both genders in Iranian adults [27, 28]; (2) reduced high-density lipoprotein cholesterol (HDL-C) $<50 \mathrm{mg} / \mathrm{dl}$ in women, $<40$ in men, or receiving medications for reduced HDL-C; (3) elevated triglyceride (TG) levels $\geq 150 \mathrm{mg} / \mathrm{dl}$ or receiving medications for elevated TG; (4) elevated blood pressure ( $\geq 130 \mathrm{mmHg}$ SBP or $\geq 85 \mathrm{mmHg}$ DBP) or receiving antihypertensive medications and (5) elevated FBG $\geq 100 \mathrm{mg} /$ dl or receiving medications for elevated FBG [29]. A trained interviewer used pre-test questionnaires for collecting sociodemographic data, physical activity, and smoking status. Smoking status was categorized into two groups: 1) non-smokers and 2) current smokers (regular or irregular smokers). Information on physical activity was collected with the Iranian version of the Modifiable Activity Questionnaire (MAQ) [30]. The psychometric properties of the Iranian version of the MAQ have been reported previously, and the Iranian version of the questionnaire has been found to have high reliability and moderate validity [31]. In this questionnaire, the number of times and duration of any physical activity is asked. The levels of physical activity have been calculated as MET minutes/ week and based on this, the amount of physical activity of individuals divided into three groups including low activity (MET< $600 \mathrm{~min} /$ week), moderate $(600 \leq \mathrm{MET}<3000 \mathrm{~min} /$ week) and high (MET $\geq 3000 \mathrm{~min} /$ week).

The ethics committee of the Research Institute for Endocrine Sciences (RIES) of Shahid Beheshti University of Medical Sciences approved the current study. Before initiation of the study, all participants provided written informed consent.

\section{Statistical analysis}

The cluster analysis method, a robust statistical method to classify populations, can extract homogenous groups of people used to cluster children. Two-step cluster analysis as a special method which is utilized for both categorical and continues variables was used in this study. Based on Bayesian Information Criteria (BIC), Akaike Information Criteria (AIC) and also considering the interpretability of extracted clusters the optimal number of clusters were stabilized [32]. Two separate cluster 
analysis were conducted to group children according to maternal and parental risk factors. Based on the parental risk factors, children were classified in four risk groups, including high or low risk maternal clusters and high or low risk paternal clusters. The distribution of categorical factors and the mean of continuous variables were compared between recognized clusters, using the Chi-square test and the independent T-test respectively. Kaplan-
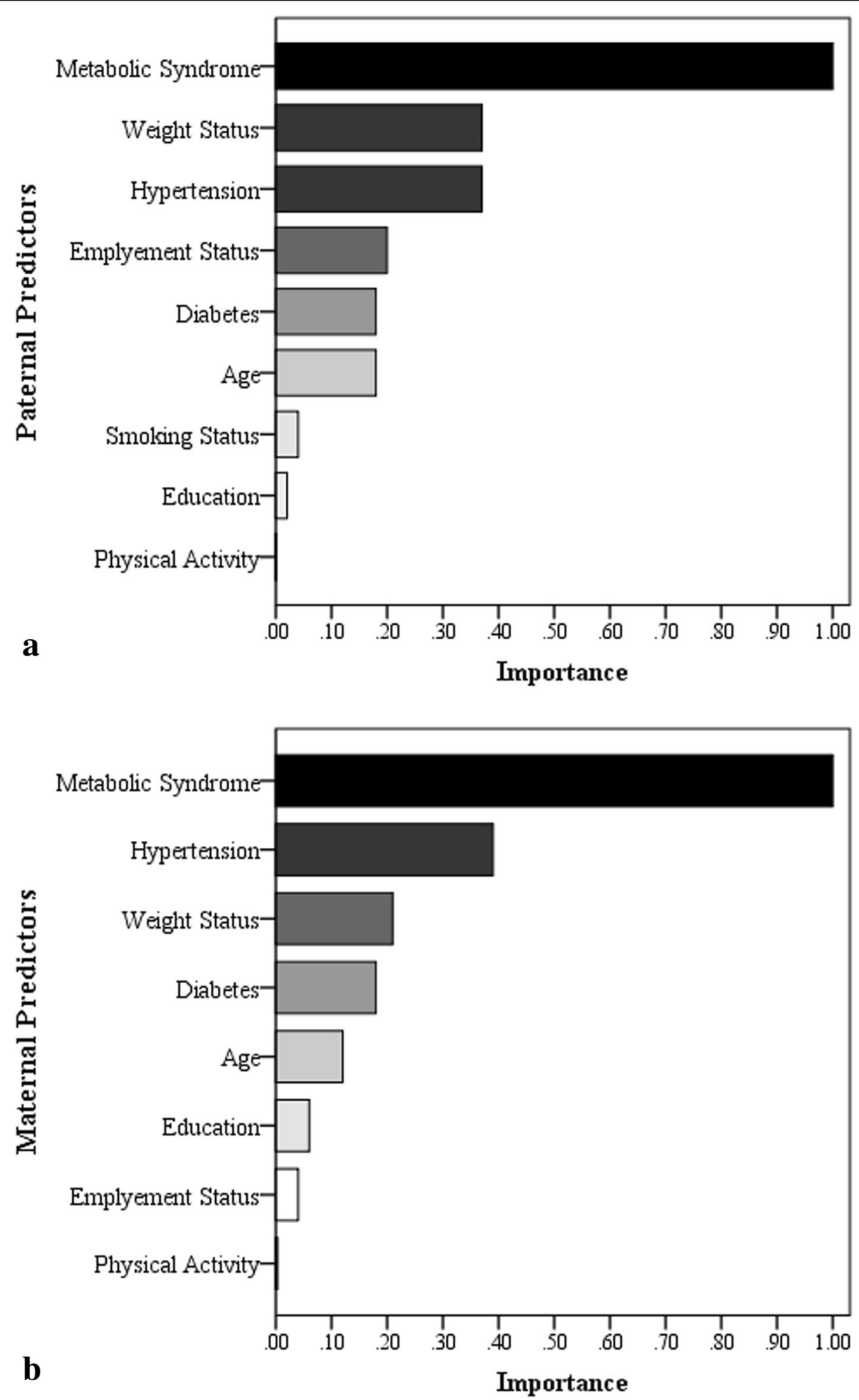

Fig. 2 Importance of various factors in the children clustering according to a paternal and $\mathbf{b}$ maternal risk factors associated with hypertension 
Meier curve, Log-rank test and cox proportional hazards model was used to evaluate the parental cluster effects on the incidence of hypertension. In the multiple analysis children's sex, age and BMI were adjusted as potential confounders. The assumption of proportional hazards in survival cox models was checked by graphically (log minus log graph) and tested by schoenfeld residuals too [33]; $P<0.05$ was set as significance level and statistical analysis were done by STATA 13 and IBM SPSS 23.

\section{Results}

The mean age of children was $13.96 \pm 2.89$ years, and $51.2 \%(n=854)$ were girls. The median follow-up time was 15.8 years. Parental characteristics, namely, age, education, employment status, MetS status, HTN, diabetes, and body weight status, were used to identify low and high-risk clusters. Figure 2 demonstrates the importance level of mentioned factors in the classification of parental risk clusters. In both parents, the most influential factor was MetS with an importance value of 1 , followed by

Table 1 Children's and mothers' characteristics across low and high-risk maternal clusters: Tehran Lipid and Glucose Study (TLGS)

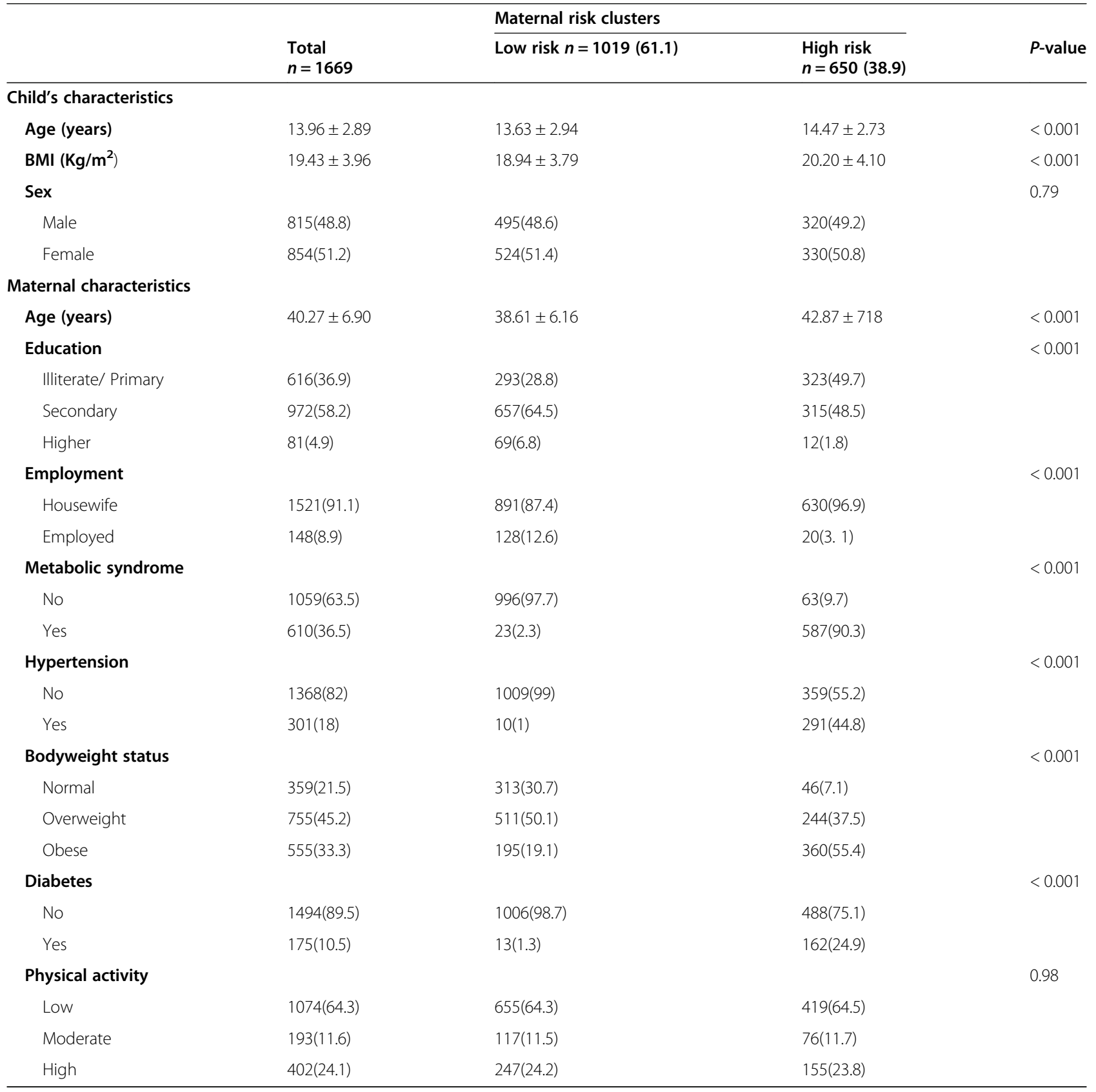


parental HTN and weight status, among other important, significant factors.

Table 1 shows the maternal characteristics of study participants according to their risk clusters. Most children were included in the low-risk maternal cluster (61.1\%). As indicated, except for children's sex and maternal physical activity, all other maternal characteristics were significantly different in the low and high-risk clusters. The mean age of mothers in the high-risk cluster, was significantly higher than in the low-risk cluster. In addition, compared to the low-risk cluster, higher percentages of mothers in the high-risk cluster had primary levels of education, MetS, HTN, diabetes, and obesity. The rate of stay-at-home mothers in the highrisk cluster was also significantly higher than in the lowrisk cluster.

Table 2 Children's and fathers' characteristics across low and high-risk paternal clusters: Tehran Lipid and Glucose Study (TLGS)

\begin{tabular}{|c|c|c|c|c|}
\hline & \multirow[b]{2}{*}{$\begin{array}{l}\text { Total } \\
n=1669\end{array}$} & \multicolumn{2}{|c|}{ Paternal risk clusters } & \multirow[b]{2}{*}{$P$-value } \\
\hline & & $\begin{array}{l}\text { Low risk } \\
n=760(45.5)\end{array}$ & $\begin{array}{l}\text { High risk } \\
909(54.5)\end{array}$ & \\
\hline \multicolumn{5}{|l|}{ Child's characteristics } \\
\hline Age (years) & $13.96 \pm 2.89$ & $13.50 \pm 2.67$ & $14.34 \pm 2.86$ & $<0.001$ \\
\hline BMI $\left(\mathrm{Kg} / \mathrm{m}^{2}\right)$ & $19.43 \pm 3.96$ & $18.79 \pm 3.75$ & $19.96 \pm 4.00$ & \\
\hline Sex & & & & 0.32 \\
\hline Male & $815(48.8)$ & $361(47.5)$ & $454(49.9)$ & \\
\hline Female & $854(51.2)$ & $399(52.5)$ & $455(50.1)$ & \\
\hline \multicolumn{5}{|l|}{ Paternal characteristics } \\
\hline Age (years) & $47.20 \pm 7.98$ & $44.47 \pm 6.71$ & $49.46 \pm 8.24$ & $<0.001$ \\
\hline Education & & & & $<0.001$ \\
\hline Illiterate/ Primary & 539.(32.3) & $209(27.5)$ & $330(36.3)$ & \\
\hline Secondary & $875(52.4)$ & $424(55.8)$ & $451(49.6)$ & \\
\hline Higher & $255(15.3)$ & $127(16.7)$ & $128(14.1)$ & \\
\hline Employment & & & & $<0.001$ \\
\hline Housewife & $236(14.1)$ & $12(1.6)$ & $224(24.6)$ & \\
\hline Employed & 1433(85.9) & 748(98.4) & $685(75.4)$ & \\
\hline Metabolic syndrome & & & & $<0.001$ \\
\hline No & $994(59.6)$ & $760(100)$ & $234(25.7)$ & \\
\hline Yes & $675(40.4)$ & $00(0.0)$ & $676(74.3)$ & \\
\hline Hypertension & & & & $<0.001$ \\
\hline No & 1333(79.9) & $760(100)$ & $573(63)$ & \\
\hline Yes & $336(20.1)$ & $0(0.0)$ & $336(37)$ & \\
\hline Bodyweight status & & & & $<0.001$ \\
\hline Normal & $630(37.7)$ & $442(58.2)$ & 188(20.7) & \\
\hline Overweight & $774(46.4)$ & $310(40.8)$ & $464(51.0)$ & \\
\hline Obese & 265(15.9) & $8(1.1)$ & $2.57(28.3)$ & \\
\hline Diabetes & & & & $<0.001$ \\
\hline No & 1493(89.5) & $760(100)$ & 733(80.6) & \\
\hline Yes & $176(10.5)$ & $0(0.0)$ & 176(19.4) & \\
\hline Smoking status & & & & $<0.001$ \\
\hline No & 1152(69.0) & $473(62.2)$ & 679(74.7) & \\
\hline Yes & $517(31.0)$ & $227(37.8)$ & $230(25.3)$ & \\
\hline Physical activity & & & & 0.21 \\
\hline Low & $1082(64.8)$ & $496(65.3)$ & $586(64.5)$ & \\
\hline Moderate & 255(15.3) & 125(16.4) & 130(14.3) & \\
\hline High & $332(19.9)$ & 139(18.3) & 193(21.2) & \\
\hline
\end{tabular}


Table 2 displays paternal characteristics of study participants by risk clusters. More than half of the children were included in the paternal high-risk cluster (54.5\%). Like maternal characteristics, except for children's sex and paternal physical activity, all other paternal characteristics were significantly different in the low and highrisk clusters. The mean age of fathers was significantly higher in the high-risk cluster compared to the low-risk cluster. Moreover, higher percentages of fathers had a primary level of education, MetS, HTN, diabetes, and obesity in the high-risk cluster compared to the low-risk one. However, the percentage of fathers' smoking was significantly higher in the low-risk cluster than in the high-risk cluster.

Information on incidence rates by sex and parental cluster groups are presented in Table 3. Crude incidence rates (per 10,000 person-years) of HTN were 86 (95\% CI: 71-106) and 38 (95\% CI: 29-52) in boys and girls, respectively. Moreover, incidence rates (per 10,000 person-years) of HTN were 50 (95\% CI: 40-63) and 80 (95\% CI: 64-102) in the maternal low- and high-risk clusters, respectively. The incidence rates (per 10,000 person-years) of HTN in paternal low- and high-risk clusters were 53 (95\% CI: 41-70) and 68 (95\% CI: 56$84)$, respectively.

According to paternal and maternal risk clusters, Kaplan-Meier curves for incidence hypertention in children were presented respectively in Fig. $3 a$ and b. The log-rank test showed a significant difference in the incidence of hypertension only for maternal risk clusters $(p=0.005)$. The association between parental risk clusters and incidence of hypertension in children using Cox proportional hazard models is presented in Table 4 . Models 1 and 2 are unadjusted models for maternal and paternal risk clusters, respectively. Model 3 and 4 were models adjusted for child's age, sex, and BMI. Model 5 is the final model that includes both parental risk clusters and is adjusted for child's age, sex, and BMI. Findings

Table 3 Incidence rates (per 10,000 person-years) of hypertension, by sex and parental clusters

\begin{tabular}{lll}
\hline Variables & Incidence Rate & $\mathbf{9 5 \% ~ C l}$ \\
\hline Sex & 86 & $71-106$ \\
$\quad$ Male & 38 & $29-52$ \\
$\quad$ Female & & \\
Maternal risk clusters & 50 & $40-63$ \\
Low-risk & 80 & $64-102$ \\
High-risk & & \\
Paternal risk clusters & 53 & $41-70$ \\
Low risk & 68 & $56-84$ \\
High risk & 61 & $52-73$ \\
Total & &
\end{tabular}

indicate that only maternal clusters' effect was significant on the incidence of HTN in children in both unadjusted ( $\mathrm{HR}=1.59,95 \%$ CI: $1.15-2.21 ; p=0.005)$ and adjusted models $(\mathrm{HR}=1.46,95 \% \mathrm{CI}: 1.05-2.03 ; p=0.025)$. In the final model, significant factors influencing the incidence of HTN in children were maternal cluster $(\mathrm{HR}=1.44$, 95\% CI: 1.03-2.02; $p=0.03$, Ref: low risk cluster), children's sex (HR $=0.44,95 \%$ CI: 0.31-0.62; $p<0.001$, Ref: male) and children's BMI (HR $=1.09,95 \% \mathrm{CI}: 1.05-1.13$; $p<0.001$.

\section{Discussion}

The current study investigated the association of maternal and paternal risk clusters with the incidence of HTN in school-aged children over a 13-year follow-up. Our results indicate cardio-metabolic risk factors as the most important variable distinguishing parental risk clusters in both parents. Furthermore, another finding was the significant prognostic values of maternal risk clusters to predict HTN in their children, which was not supported by our data regarding the paternal risk cluster. In addition, boys compared to girls and children with higher BMI were more likely to be hypertensive in the future.

In the current study regarding socio-demographic characteristics of parents, only employment status in fathers and age in both parents played important roles, a result consistent with previous data, suggesting the significant effect of family socioeconomic status (SES) defined as parental employment and family income on children's general health and risk of CVD development in adulthood [34-36]. Accordingly, previous findings in Iran showed that moderate and low familial, economic status could increase the incidence of HTN in schoolaged children [18]. The Young Finns Study tracking BP in children for 30 years until adulthood also indicated the contribution of parental occupation status in the elevation of offspring's BP [37]. A potential explanation might be that parental unemployment and low income could result in mental and physical risk factors such as anxiety, depression, and obesity, resulting in increased $\mathrm{BP}$ in their children [35, 38].

According to current findings, in both parents, the most important factors in distinguishing high and low parental risk clusters were essentially cardio-metabolic risk factors, including MetS, HTN, and weight status, while physical activity was the least significant one. Most previous studies attempting to unveil the impact of parental cardio-metabolic risk factors in association with childhood HTN have considered these factors separately and underscored the importance of the family history of HTN and parental weight status in increasing risk of HTN in their children [7, 12, 39-41]. Even in Iran, HTN and obesity of parents were found to be potential risk 


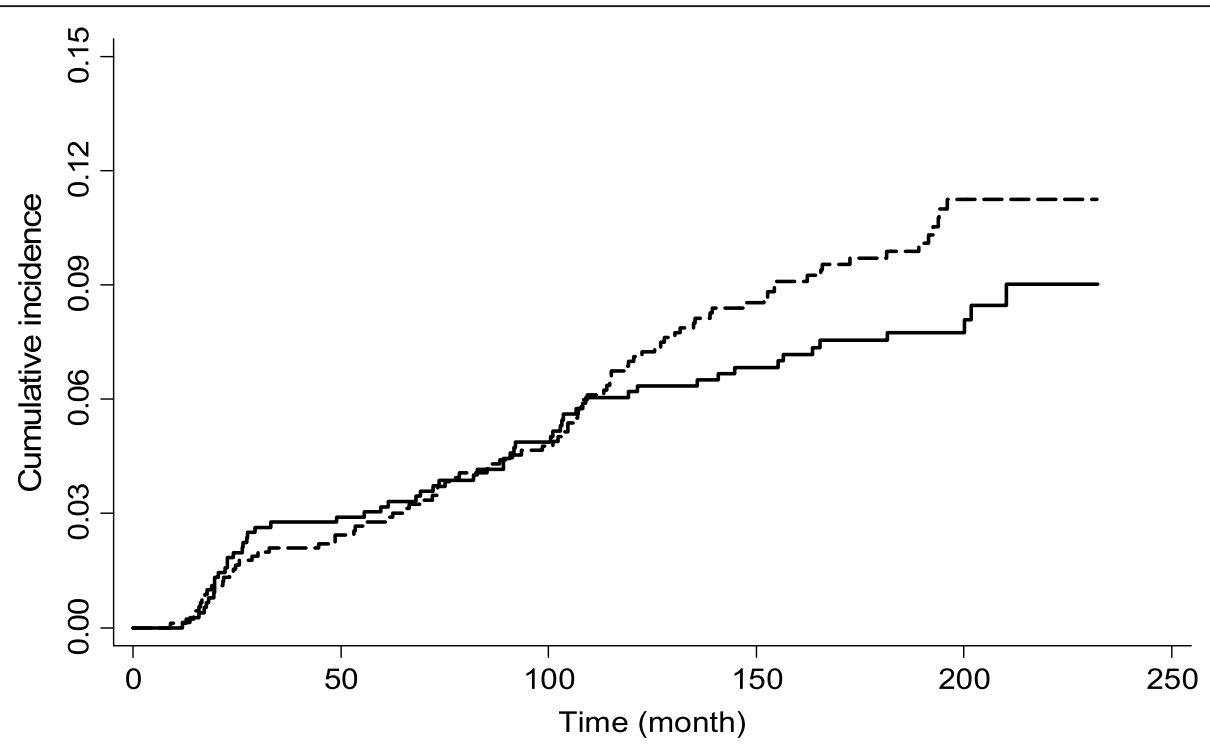

a.

Low risk - - - - High risk

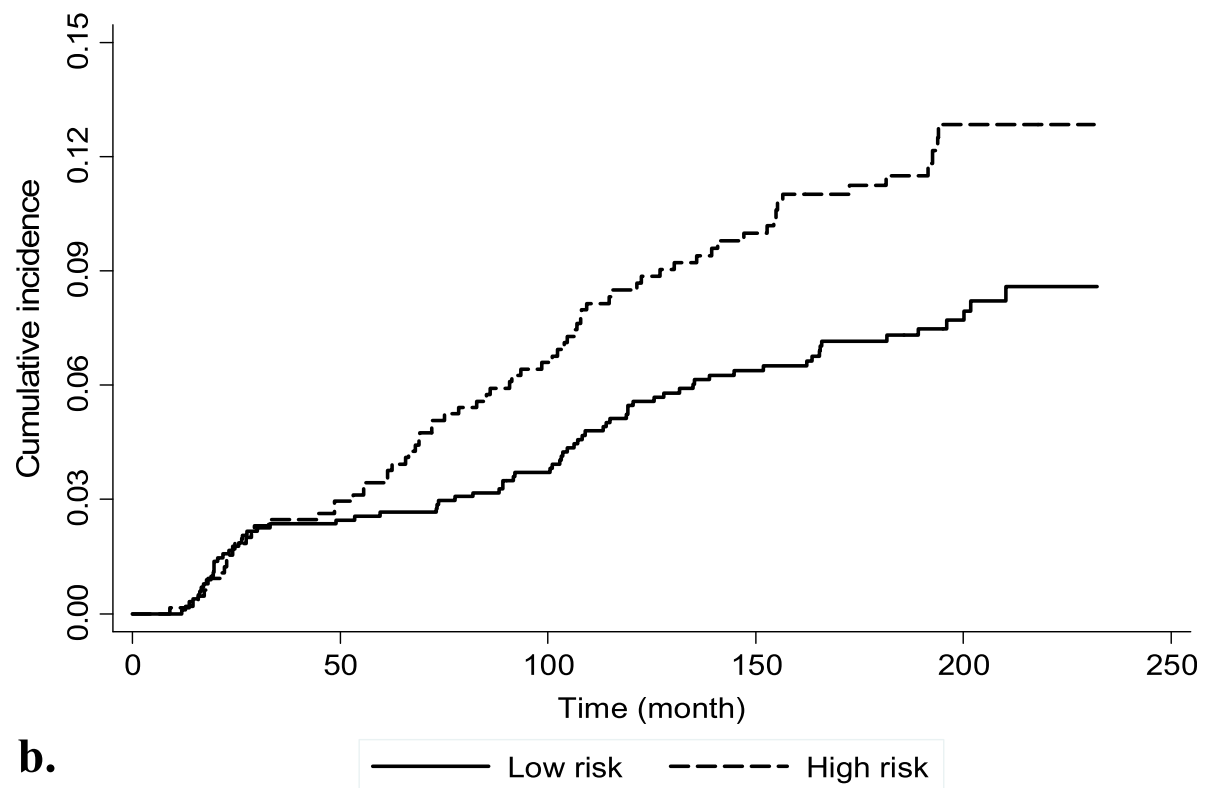

Fig. 3 Kaplan-Meier cumulative incidence curve of hypertension in children according to different cluster groups related to $\mathbf{a}$ fathers' and $\mathbf{b}$ mothers' characteristics; the log-rank test $p$-value were 0.154 and 0.005 , respectively

factors resulting in elevated BP in children [17]. Most existing studies have not considered the synergic effects of the parental cardio-metabolic cluster on the BP level of their young offspring. However, in line with our findings, a cohort study in Japan revealed that clustering of maternal history of cardiometabolic disorders including HTN, diabetes, and dyslipidemia makes individuals more susceptible to clustering of these disorders in the future [42]. Meanwhile, another study in Germany referred to the interrelation of parental HTN, obesity, and smoking status as a combination of risk factors that could predispose children to HTN [15].

In the current study, only the maternal risk cluster appeared to have prognostic value in predicting HTN incidence in children, not the paternal one. The association between maternal HTN and weight status and children's BP level has been documented previously [43]. However, limited data exist supporting the role of maternal cardio-metabolic characteristics as a risk cluster to predict offspring's HTN; among those existing studies, a 
Table 4 Hazard Ratios (HRs) and 95\% confidence intervals for incidence of hypertension based on parental risk clusters

\begin{tabular}{|c|c|c|c|c|}
\hline Models & Predictors & Risk clusters & HR $(95 \% \mathrm{Cl})$ & $P$-value \\
\hline \multirow[t]{2}{*}{ Model 1} & Maternal cluster & Low risk (ref) & 1 & . \\
\hline & & High risk & $1.59(1.15-2.21)$ & 0.005 \\
\hline \multirow[t]{2}{*}{ Model 2} & Paternal cluster & Low risk (ref) & 1 & . \\
\hline & & High risk & $1.27(0.91-1.78)$ & 0.16 \\
\hline \multirow[t]{6}{*}{ Model 3} & Maternal cluster & Low risk (ref) & 1 & . \\
\hline & & High risk & $1.46(1.05-2.03)$ & 0.025 \\
\hline & Sex & Male (ref) & & . \\
\hline & & Female & $0.44(0.31-0.62)$ & $<0.001$ \\
\hline & Age & & $0.97(0.91-1.03)$ & 0.30 \\
\hline & BMI & & $1.09(1.05-1.14)$ & $<0.001$ \\
\hline \multirow[t]{6}{*}{ Model 4} & Paternal cluster & Low risk (ref) & 1 & . \\
\hline & & High risk & $1.14(0.81-1.60)$ & 0.44 \\
\hline & Sex & Male (ref) & & . \\
\hline & & Female & $0.44(0.31-0.62)$ & $<0.001$ \\
\hline & Age & & $0.97(0.91-1.03)$ & 0.34 \\
\hline & $\mathrm{BMI}$ & & $1.10(1.06-1.14)$ & $<0.001$ \\
\hline \multirow[t]{8}{*}{ Model 5} & Maternal cluster & Low risk (ref) & 1 & . \\
\hline & & High risk & $1.44(1.03-2.02)$ & 0.03 \\
\hline & Paternal cluster & Low risk (ref) & 1 & . \\
\hline & & High risk & $1.09(0.77-1.53)$ & 0.63 \\
\hline & Sex & Male (ref) & 1 & . \\
\hline & & Female & $0.44(0.31-0.62)$ & $<0.001$ \\
\hline & Age & & $0.96(0.90-1.03)$ & 0.29 \\
\hline & $\mathrm{BMI}$ & & $1.09(1.05-1.13)$ & $<0.001$ \\
\hline
\end{tabular}

The effects of child's age, sex, and BMI were adjusted in multiple models (models 3, 4, and 5)

cohort study in Japan revealed that CVD outcomes including HTN in adult offspring were strongly influenced by the synergic effect of maternal cardio-metabolic history but not the paternal history of these disorders [42]. In Iran, the Isfahan Cohort Study also emphasizes the significance of screening maternal cerebrovascular diseases, including HTN, diabetes, hyperlipidemia, and obesity, in developing these risk factors in female children [44]. A combination of interrelated mechanisms, including environmental, genetic, and epigenetic factors, may elucidate the prognostic value of maternal cardiometabolic risk clusters in association with offspring's HTN incidence [42]. Previous data suggest that healthy children of hypertensive mothers, compared to those without a family history of HTN, tend to have higher insulin levels which could explain the common pathway for developing CVD in those children [43]. Meanwhile, mitochondrial DNA-mediated inheritance could be a genetic explanation of maternal role in transmitting cardio-metabolic phenotypes including HTN to their children [45]. Greater shared environment with mothers resulting in similar lifestyles and behaviors, including dietary habits, may also contribute to these components [46].

In line with previous data, male children and those with high BMI in this study appeared to be at greater risk of developing HTN in the future. The predisposing role of gender in children to sustain high BP has been proposed in previous studies, implicating the higher incidence of HTN in male children $[8,10]$. A systematic review on the prevalence of HTN in 122,053 adolescents, consistent with the current findings, also demonstrated that besides the methodological difference in studies, male adolescents have higher odds of high BP, especially in low- and middle-income countries [10]. Although most previous studies in Iran indicate higher BP incidence in boys $[17,47,48]$, a few found only slightly significant differences or even contradictory results [18, 49]. The correlation between obesity and HTN in children is well established in literature which is in line with current findings $[8,50]$. Studies from different parts of Iran have also documented the influential impact of high $\mathrm{BMI}$ on increasing BP in this age group [17, 18, 21, 48].

Among strengths of the current study, the large sample size, its longitudinal nature accompanied by longterm follow-up, and data collection for both parents are of significance. Some limitations of this study should also be mentioned. In this study, some parental factors, including uric acid levels, dietary intakes, and family income, were unavailable and were not included in the study analysis. Also, conducting the current study on an urban population could reduce the generalizability of the present findings, for which further research in suburban and rural areas is recommended.

In conclusion, the current results underscore the prognostic value of maternal risk cluster in predicting the incidence of HTN in their offspring. Highlighting this finding will be valuable for health policymakers to identify the most vulnerable children for HTN and designing preventive strategies.

\section{Abbreviations}

BP: Blood pressure; BMI: Body mass index; CVD: Cardiovascular diseases; $\mathrm{Cl}$ : Confidence interval; HRs: Hazard Ratios; HTN: Hypertension; MetS: Metabolic syndrome; SES: Socio-economic status; TLGS: Tehran Lipid and Glucose Study; WHO: World health organization

\section{Acknowledgements}

The authors would like to express their appreciation to all participants who made this study possible wish to acknowledge Ms. Niloofar Shiva for critical editing of English grammar and syntax of the manuscript.

\section{Authors' contributions}

PA, MR and SJ-F designed the study. MK and LCh participated in acquisition of data and carried out the statistical analysis. PA, MR and SJ-F contributed to interpretation of data. PA, MR, SJ-F and RE drafted the manuscript. FA supervised and revised the manuscript. All authors read and approved the final manuscript. 


\section{Funding}

There are no funding resources for this research.

\section{Availability of data and materials}

The datasets used and/or analyzed during the current study are available from the corresponding author on reasonable request.

\section{Declarations}

\section{Ethics approval and consent to participate}

This study was approved by the research ethics committee of the Research Institute for Endocrine Sciences (RIES), Shahid Beheshti University of Medical Sciences. All procedures were in accordance with the ethical standards of the institutional and/or national research committee and with the 1964 Helsinki declaration and its later amendments or comparable ethical standards.

Informed consent was obtained from all participants. Before data collection, both children and parents were informed about the study procedure and its aims, and if the child and parent agreed to participate in the study, parents were asked to sign a written consent form.

\section{Consent for publication}

Not applicable.

\section{Competing interests}

The authors declare that they have no competing interests.

\section{Author details}

${ }^{1}$ Research Center for Social Determinants of Health, Research Institute for Endocrine Sciences, Shahid Beheshti University of Medical Sciences, Tehran, Iran. ${ }^{2}$ Biostatistics Department, Research Institute for Endocrine Sciences, Shahid Beheshti University of Medical Sciences, Tehran, Iran. ${ }^{3}$ Endocrine Research Center, Research Institute for Endocrine Sciences, Shahid Beheshti University of Medical Sciences, P.O.Box: 19395-4763, Tehran, Islamic Republic of Iran.

\section{Received: 10 August 2020 Accepted: 7 July 2021}

Published online: 17 August 2021

\section{References}

1. Organization WH: A global brief on hypertension: silent killer, global public health crisis: World health day 2013 (2013). 2018.

2. Health-topics hypertension [https://www.who.int/health-topics/ hypertension]

3. Oori MJ, Mohammadi F, Norozi K, Fallahi-Khoshknab M, Ebadi A, Gheshlagh RG. Prevalence of HTN in Iran: Meta-analysis of published studies in 20042018. Curr Hypertens Rev. 2019:15(2):113-22. https://doi.org/10.2174/15734 02115666190118142818

4. Amiri P, Vahedi-Notash G, Naseri P, Khalili D, Nazari SSH, Mehrabi Y, et al. National trends of pre-hypertension and hypertension among Iranian adolescents across urban and rural areas (2007-2011). Biol Sex Differ. 2019; 10(1):15. https://doi.org/10.1186/s13293-019-0230-1.

5. Rao G. Diagnosis, epidemiology, and management of hypertension in children. Pediatrics. 2016;138(2):e20153616. https://doi.org/10.1542/peds.201 5-3616.

6. Lee MH, Kang DR, Kim HC, Ahn SV, Khaw K-T, Suh I. A 24-year follow-up study of blood pressure tracking from childhood to adulthood in Korea: the Kangwha study. Yonsei Med J. 2014;55(2):360-6. https://doi.org/10.3349/ ymj.2014.55.2.360.

7. Manios $Y$, Karatzi K, Moschonis G, loannou G, Androutsos O, Lionis C, et al. Lifestyle, anthropometric, socio-demographic and perinatal correlates of early adolescence hypertension: the healthy growth study. Nutr Metab Cardiovasc Dis. 2019;29(2):159-69. https://doi.org/10.1016/j.numecd.2018.10. 007.

8. Ewald DR, Haldeman LA. Risk factors in adolescent hypertension. Glob Pediatr Health. 2016;3:2333794X15625159.

9. Anyaegbu El, Dharnidharka VR. Hypertension in the teenager. Pediatr Clin. 2014;61(1):131-51. https://doi.org/10.1016/j.pcl.2013.09.011.

10. de Moraes ACF, Lacerda MB, Moreno LA, Horta BL, Carvalho HB. Prevalence of high blood pressure in 122,053 adolescents: a systematic review and meta-regression. Medicine. 2014;93(27):e232. https://doi.org/10.1097/MD 0000000000000232.

11. Brambilla P, Bedogni G, Pietrobelli A, Cianfarani S, Agostoni C. Predictors of blood pressure at 7-13 years: the "new millennium baby" study. Nutr Metab Cardiovasc Dis. 2016;26(8):706-12. https://doi.org/10.1016/j.numecd.2015.11. 005.

12. Gupta-Malhotra M, Hashmi SS, Barratt MS, Milewicz DM, Shete S. Familial aggregation of first degree relatives of children with essential hypertension. Blood Press. 2018;27(5):289-96. https://doi.org/10.1080/08037051.2018.1463 818.

13. Kwok MK, Schooling CM, Subramanian SV, Leung GM, Kawachi I. Pathways from parental educational attainment to adolescent blood pressure. J Hypertens. 2016;34(9):1787-95. https://doi.org/10.1097/HJH.0000000000001 003.

14. van den Berg G, van Eijsden M, Galindo-Garre F, Vrijkotte TG, Gemke RJ. Explaining socioeconomic inequalities in childhood blood pressure and prehypertension: the ABCD study. Hypertension. 2013;61(1):35-41. https:// doi.org/10.1161/HYPERTENSIONAHA.111.00106.

15. Simonetti GD, Schwertz R, Klett M, Hoffmann GF, Schaefer F, Wühl E. Determinants of blood pressure in preschool children: the role of parental smoking. Circulation. 2011;123(3):292-8. https://doi.org/10.1161/CIRCULA TIONAHA. 110.958769.

16. Kelishadi R, Hashemipour M, Bashardoost N. Blood pressure in children of hypertensive and normotensive parents. Indian Pediatr. 2004;41(1):73-8.

17. Kelishadi R, Ardalan G, Gheiratmand R, Majdzadeh R, Delavari A, Heshmat R, et al. Blood pressure and its influencing factors in a national representative sample of Iranian children and adolescents: the CASPIAN study. Eur J Cardiovasc Prev Rehabil. 2006;13(6):956-63. https://doi.org/10.1097/01.hjr. 0000219109.17791.b6.

18. Ebrahimi $\mathrm{H}$, Emamian $\mathrm{MH}$, Hashemi $\mathrm{H}$, Fotouhi A. Prevalence of prehypertension and hypertension and its risk factors in Iranian school children: a population-based study. J Hypertens. 2018;36(9):1816-24. https:// doi.org/10.1097/HJH.0000000000001789.

19. Qaddumi J, Holm M, Alkhawaldeh A, Albashtawy M, Omari OA, Batiha A-M, et al. Prevalence of hypertension and pre-hypertension among secondary school students. Int J Adv Nurs Stud. 2016;5(2):240. https://doi.org/10.14419/ ijans.v5i2.6878.

20. ÖNSÜZ FM, Demir F. Prevalence of hypertension and its association with obesity among schoolchildren aged 6-15 living in Sakarya Province in Turkey. Turk J Med Sci. 2015;45(4):907-12. https://doi.org/10.3906/sag-1407-120.

21. Basiratnia M, Derakhshan D, Ajdari S, Saki F. Prevalence of childhood obesity and hypertension in south of Iran. Iran J Kidney Dis. 2013;7(4):282-9.

22. Azizi F, Rahmani M, Emami H, Mirmiran P, Hajipour R, Madjid M, et al. Cardiovascular risk factors in an Iranian urban population: Tehran lipid and glucose study (phase 1). Soz Präventivmed. 2002;47(6):408-26. https://doi. org/10.1007/s000380200008

23. Azizi F, Ghanbarian A, Momenan AA, Hadaegh F, Mirmiran P, Hedayati M, et al. Prevention of non-communicable disease in a population in nutrition transition: Tehran lipid and glucose study phase II. Trials. 2009;10(1):5. https://doi.org/10.1186/1745-6215-10-5.

24. Azizi F, Madjid M, Rahmani M, Emami H, Mirmiran P, Hadjipour R. Tehran lipid and glucose study (TLGS): rationale and design. Iran J Endocrinol Metab. 2000;2(2):77-86.

25. Rosner B, Prineas R, Loggie J, Daniels S. Blood pressure nomograms for children and adolescents, by height, sex, and age, in the United States. Pediatr. 1993;123(6):871-86. https://doi.org/10.1016/S0022-3476(05)80382-8.

26. VOORS AW, WEBBER LS, FRERICHS RR, BERENSON GS. Body height and body mass as determinants of basal blood pressure in children - the Bogalusa heart study. Am J Epidemiol. 1977;106(2):101-8. https://doi.org/10.1093/ oxfordjournals.aje.a112439.

27. Delavari A, Forouzanfar MH, Alikhani S, Sharifian A, Kelishadi R. First nationwide study of the prevalence of the metabolic syndrome and optimal cutoff points of waist circumference in the Middle East: the national survey of risk factors for noncommunicable diseases of Iran. Diabetes Care. 2009;32(6):1092-7. https://doi.org/10.2337/dc08-1800.

28. AZIZI F, Hadaegh F, KHALILI D, Esteghamati A, HOSSEIN PF, Delavari A, et al. Appropriate definition of metabolic syndrome among Iranian adults: report of the Iranian National Committee of obesity; 2010.

29. Alberti KGMM, Eckel RH, Grundy SM, Zimmet PZ, Cleeman Jl, Donato KA, et al. Harmonizing the metabolic syndrome. Circulation. 2009;120(16):16405. https://doi.org/10.1161/CIRCULATIONAHA.109.192644. 
30. Kriska AM, Knowler WC, LaPorte RE, Drash AL, Wing RR, Blair SN, et al. Development of questionnaire to examine relationship of physical activity and diabetes in Pima Indians. Diabetes Care. 1990;13(4):401-11. https://doi. org/10.2337/diacare.13.4.401.

31. Momenan AA, Delshad M, Sarbazi N, REZAEI GN, Ghanbarian A, AZIZI F. Reliability and validity of the modifiable activity questionnaire (MAQ) in an Iranian urban adult population; 2012.

32. Bacher J, Wenzig K, Vogler M. SPSS TwoStep cluster-a first evaluation; 2004

33. Klein JP, Moeschberger ML. Survival analysis: techniques for censored and truncated data: Springer Science \& Business Media; 2006.

34. Kuhlthau KA, Perrin JM. Child health status and parental employment. Arch Pediatr Adolesc Med. 2001;155(12):1346-50. https://doi.org/10.1001/a rchpedi.155.12.1346

35. Schaller J, Zerpa M. Short-run effects of parental job loss on child health Am J Health Econ. 2019;5(1):8-41. https://doi.org/10.1162/ajhe_a_00106.

36. Doom JR, Mason SM, Suglia SF, Clark CJ. Pathways between childhood/ adolescent adversity, adolescent socioeconomic status, and long-term cardiovascular disease risk in young adulthood. Soc Sci Med. 2017;188:16675. https://doi.org/10.1016/j.socscimed.2017.06.044.

37. Juhola J, Oikonen M, Magnussen CG, Mikkilä V, Siitonen N, Jokinen E, et al. Childhood physical, environmental, and genetic predictors of adult hypertension: the cardiovascular risk in young Finns study. Circulation. 2012; 126(4):402-9. https://doi.org/10.1161/CIRCULATIONAHA.111.085977.

38. East P, Doom J, Delker E, Blanco E, Burrows R, Correa-Burrows P, Lozoff B, Gahagan S. Childhood socioeconomic hardship, family conflict, and young adult hypertension: the Santiago longitudinal study. Soc Sci Med. 2020;253: 112962. https://doi.org/10.1016/j.socscimed.2020.112962.

39. Kawabe H, Azegami T, Takeda A, Kanda T, Saito I, Saruta T, et al. Features of and preventive measures against hypertension in the young. Hypertens Res. 2019;42(7):935-48. https://doi.org/10.1038/s41440-019-0229-3.

40. Xu R, Zhang X, Zhou Y, Wan Y, Gao X. Parental overweight and hypertension are associated with their children's blood pressure. Nutr Metab. 2019;16(1):35. https://doi.org/10.1186/s12986-019-0357-4.

41. Mitsumata K, Saitoh S, Ohnishi H, Akasaka H, Miura T. Effects of parental hypertension on longitudinal trends in blood pressure and plasma metabolic profile: mixed-effects model analysis. Hypertension. 2012;60(5): 1124-30. https://doi.org/10.1161/HYPERTENSIONAHA.112.201129.

42. Wada K, Tamakoshi K, Yatsuya H, Otsuka R, Murata C, Zhang H, et al. Association between parental histories of hypertension, diabetes and dyslipidemia and the clustering of these disorders in offspring. Prev Med. 2006;42(5):358-63. https://doi.org/10.1016/j.ypmed.2006.01.015.

43. Rodríguez-Moran M, Aradillas-García C, Simental-Mendia LE, MonrealEscalante $E$, de la Cruz ME, Dávila Esqueda ME, et al. Family history of hypertension and cardiovascular risk factors in prepubertal children. Am J Hypertens. 2010;23(3):299-304. https://doi.org/10.1038/ajh.2009.257.

44. Khosravi A, Behjati M, Dianatkhah M, Noori F, Sarrafzadegan N, Nejati M. The effect of parental medical history on the prevalence of cerebrovascular diseases in their children in an Iranian population. Basic Clin Neurosci. 2018; 9(5):367-72. https://doi.org/10.32598/ben.9.5.367.

45. Wang S, Li R, Fettermann A, Li Z, Qian Y, Liu Y, et al. Maternally inherited essential hypertension is associated with the novel 4263A> G mutation in the mitochondrial tRNAlle gene in a large Han Chinese family. Circ Res. 2011:108(7):862-70. https://doi.org/10.1161/CIRCRESAHA.110.231811.

46. Liu J, Sekine M, Tatsuse T, Hamanishi S, Fujimura Y, Zheng X. Family history of hypertension and the risk of overweight in Japanese children: results from the Toyama Birth Cohort Study. J Epidemiol. 2014;24(4):304-11. https:// doi.org/10.2188/jea.je20130149.

47. Kalantari S, Khalili D, Asgari S, Fahimfar N, Hadaegh F, Tohidi M, et al. Predictors of early adulthood hypertension during adolescence: a population-based cohort study. BMC Public Health. 2017;17(1):915. https:// doi.org/10.1186/s12889-017-4922-3.

48. Hosseini M, Ataei N, Aghamohammadi A, Yousefifard M, Taslimi S, Ataei F. The relation of body mass index and blood pressure in Iranian children and adolescents aged 7-18 years old. Iran J Public Health. 2010;39(4):126-34

49. Akbari M, Moosazadeh M, Ghahramani S, Tabrizi R, Kolahdooz F, Asemi Z, et al. High prevalence of hypertension among Iranian children and adolescents: a systematic review and meta-analysis. J Hypertens. 2017;35(6): 1155-63. https://doi.org/10.1097/HJH.0000000000001261.

50. Sorof J, Daniels S. Obesity hypertension in children: a problem of epidemic proportions. Hypertension. 2002;40(4):441-7. https://doi.org/10.1161/01.HYP. 0000032940.33466 .12 .

\section{Publisher's Note}

Springer Nature remains neutral with regard to jurisdictional claims in published maps and institutional affiliations.
Ready to submit your research? Choose BMC and benefit from:

- fast, convenient online submission

- thorough peer review by experienced researchers in your field

- rapid publication on acceptance

- support for research data, including large and complex data types

- gold Open Access which fosters wider collaboration and increased citations

- maximum visibility for your research: over $100 \mathrm{M}$ website views per year

At BMC, research is always in progress.

Learn more biomedcentral.com/submissions 